\title{
AUDITORIA EM ENFERMAGEM: PROPOSTA DE UM INSTRUMENTO
}

Sandra Honorato da Silva*

SILVA, S.H. da Auditoria em enfermagem: proposta de um instrumento. Rev. Esc. Enf. USP, São Paulo, 23(3):305-323, dez. 1989.

A autora propōe um instrumento de auditoria retrospectiva, para avaliação da assistência de enfermagem prestada a cada paciente, através da documentação da mesma. $O$ instrumento foi elaborado com base nos padröes assistenciais $e$ nas normas do planejamento da assistência de enfermagem estabelecidos para a unidade.

UNITERMOS: Auditoria em enfermagem. Assistência de enfermagem.

\section{INTRODUÇĀO}

O serviço de Enfermagem como parte integrante da estrutura administrativa do hospital, precisa propor o uso de medidas ou critérios de avaliação que expressem estatisticamente a qualidade da assistência de enfermagem prestada na instituição como esquema de controle de suas próprias atividades e embasamento para propostas de reformulação.

A auditoria é parte integrante e essencial da tecnologia de controle. É fundamental para o administrador como instrumento de vigilância, fiscalização e orientação (SÁ, 1969).

Para CHIAVENATO (1981) a auditoria é um "sistema de revisão e controle, para informar a administração sobre a eficiência e eficácia dos programas em desenvolvimento. Sua função não é somente indicar as falhas e os problemas, mas também, apontar sugestōes e soluções, assumindo em função disso um caráter eminentemente educacional".

AQUINO (1980) considera a auditoria como "uma investigação profunda sobre o sistema, em seus aspectos qualitativos e não apenas rotineiro e burocráticos, podendo ser definida como um conjunto de técnicas analíticas, destinadas a efetuar diagnósticos, prognósticos e recomendações".

\footnotetext{
* Professor Assistente do Departamento de Enfermagem MÉdico-Cirúrgica da Escola de Enfermagem da Universidade de São Paulo. Disciplinas Introdução d Enfermagem e Fundamentos de Enfermagem I.

Supervisora de Ensino e Pesquisa do Hospital Universitário da Universidade de São Paulo.
} 
A auditoria de enfermagem está sendo utilizada, na medida que se reconhece sua importância na avaliação da qualidade de assistência de enfermagem (KURCGANT 1976).

Para KRON (1978), o objetivo do processo de auditoria é a "avaliação não somente da eficácia da assistência que o paciente recebe, mas também, da integralidade e exatidão da documentação dessa assistência no prontuário".

Porém, a maior dificuldade que se apresenta em propostas de avaliação de qualidade de assistência em nosso meio, é a inexistência de critérios de avaliação.

ABDELLAH (1973) considera que critérios de avaliação podem ajudar na modificação da prática de enfermagem para melhorar o cuidado ao paciente, avaliar o efeito da ação de enfermagem na evolução do estado do paciente, e finalmente, contribuir para a definição e identificação da ciência de enfermagem.

Sempre que se trata do problema de mensuração da qualidade de assistência, alguns elementos devem ser considerados: definir o que deve ser feito, comparar o que deve ser feito com o que é feito, identificar falhas e propor açōes (PERG, 1974). Observando essa colocação, a existência de critérios de avaliação, pressupōe o estabelecimento de padrōes assistenciais e a adoçāo de um método assistencial, pois ambos determinam as bases sobre os quais se desenvolverá a prática assistencial, fornecendo conseqüentemente, os elementos indispensáveis à avaliação dos resultados alcançados.

Para acompanhar o desenvolvimento técnico e científico da enfermagem, no momento atual, há uma necessidade crescente de se desenvolverem instrumentos que mensurem a qualidade da assistência de enfermagem prestada em nossas instituições. É nesse contexto que se propōe um instrumento para auditoria retrospectiva.

\section{ELABORAÇĀO DO INSTRUMENTO DE AUDITORIA RETROSPECTIVA}

Para a obtenção de dados que permitissem uma visualização de toda a assistência de enfermagem prestada a cada paciente, elaborou-se um instrumento de auditoria, tomando-se por base os padrōes de assistência, aqueles passíveis de análise retrospectiva, definidos para a Unidade de Pediatria e as normas estabelecidas para a sistemática de assistência de enfermagem adotada na instituição. Considerou-se ainda que a assistência de enfermagem prestada a um paciente numa unidade de internação está direcionada fundamentalmente ao atendimento dos problemas de enfermagem, levantados pela própria enfermagem e dos problemas médicos que demandam açōes de enfermagem.

Para análise da assistência de enfermagem foram consideradas 6 áreas de atuação da enfermagem. 
Área I - levantamento de dados na admissão: nesta área é proposta uma análise do levantamento de dados realizado na admissão do paciente no hospital, para conhecimento de suas condições e dos problemas de enfermagem a serem inicialmente trabalhados;

Área II - prescriçōes e evoluçōes de enfermagem: nesta área é proposta uma análise de cada uma das prescrições e evoluções realizadas durante a internação, para averiguação das ações de enfermagem propostas, face aos problemas levantados, dos resultados destas ações pelas evoluçōes, assim como o levantamento de novos problemas;

Área III - anotaçōes de enfermagem: nesta área é proposta uma verificação das anotações de enfermagem, feitas por toda a equipe e análise das mesmas em relação a sua consonância com as ações propostas nas prescriçōes de enfermagem;

Área IV - execução de ordens médicas: nesta área é proposta uma verificação nas prescrições médicas e anotações de enfermagem para se constatar o cumprimento ou não de ordens médicas e as devidas justificativas. Além disso é verificado se constam das ordens médicas indicaçōes de ações de enfermagem;

Área V - procedimentos de enfermagem: nesta área é proposta uma análise dos registros de controle de: temperatura; peso; ingestão de líquidos; ingestão de alimentos; hidratação parenteral; eliminações urinárias e intestinal; vômitos e assaduras; para verificar se os mesmos estão em concordância com os padrões propostos, $\mathrm{e}$

Área VI - condiçōes de alta: nesta área é proposta uma análise das condições físicas e emocionais do paciente no momento da alta, assim como o preparo e orientação dados aos familiares no que concerne a cuidados e continuidade do tratamento.

Para garantir a objetividade na aplicação do instrumento e uniformização na obtenção de dados, foram descritos os critérios adotados para o preenchimento de cada um dos itens que compōem o instrumento. 


\section{INSTRUMENTO DE AUDITORIA DA ASSISTÊNCIA DE ENFERMAGEM}

PACIENTE

RG

SEXO

IDADE-

CLÍNICA

QUARTO

LEITO

DATA DE ADMISSĀO

DATA DE SAIDA

№ DE DIAS ANALISADOS

ANÁLISE №

ENFERMEIRA

COREN №

I - LEVANTAMENTO DE DADOS

NA ADMISSĀO

01. dados de identificação completos

02. entrevista preenchida de forma correta e por completo

03. exame físico preenchido corretamente

04. levantamento de dados permite identificar as condições do paciente: físicas

05. idem emocionais

06. levantamento de dados permite conhecimento de hábitos relacionados às necessidades: psicobiológicas

07. psicossociais

08. psicoespirituais

09. levantamento de dados datado e assinado

II - PRESCRIÇŌES E EVOLUÇÕES

DE ENFERMAGEM

10. primeira prescrição $e$ feita pela

mesma enfermeira que realizou

o levantamento

11. primeira prescrição reflete os problemas levantados, observada a prioridade do atendimento

12. "evolução de entrada" possibilita conhecer as condiçōes gerais do paciente

13. há uma prescrição diária

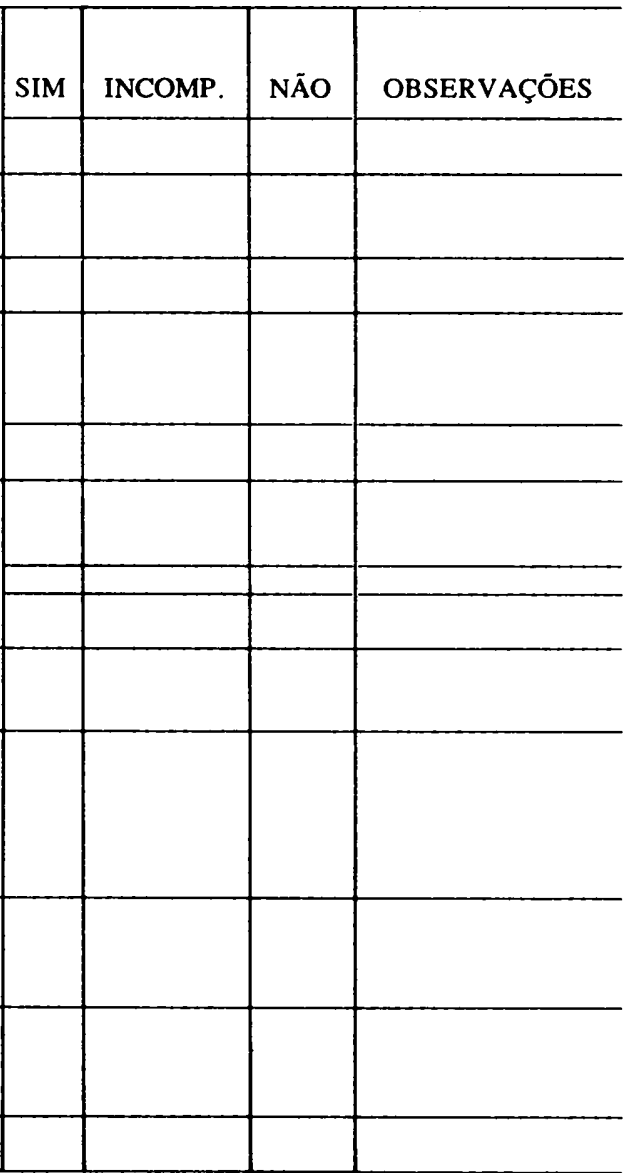


14. prescrição estruturada na seqüência determinada

15. prescrição indica o grau de dependência do paciente

16. prescrição indica açōes relacionadas ao atendimento de necessidades: psicobiológicas

\section{7. psicossociais}

18. psicoespirituais

19. prescrição aborda os problemas de enfermagem anteriores e novos

20. prescrição aponta cuidados referentes à terapeutica médica prescrita

21. prescrição tem data, horário e assinatura

22. os cuidados prescritos foram checados

23. há uma evoluçāo antecedendo cada prescriçāo

24. evolução possibilita uma visão geral das condiçōes do paciente

25. evolução fornece informaçōes dos resultados dos cuidados prestados

26. evoluçāo tem data, horário e assinatura

III - ANOT AÇŌES DE ENFERMAGEM

27. há pelo menos uma anotaçāo em cada plantão

28. anotaçōes respondem aos ítens da prescriçăo

29. anotaçōes evidenciam observaçāo de sinais e sintomas

30. horário e rubrica em cada anotação

31. anotaçāo indica quem fez

(enfermeira-técnico-auxiliar-atendente)

IV - EXECUÇÃO DE ORDENS MÉDICAS

32. medicação dada checada e rubricada

33. tratamentos checados e rubricados

34. anotada com hora e rubrica ocorrência com medicação e tratamentos

35. ordens médicas não indicam ações de enfermagem

V-PROCEDIMENTOS

36. controle de temperatura feito duas vezes ao dia no mínimo

37. peso controlado uma vez ao dia 


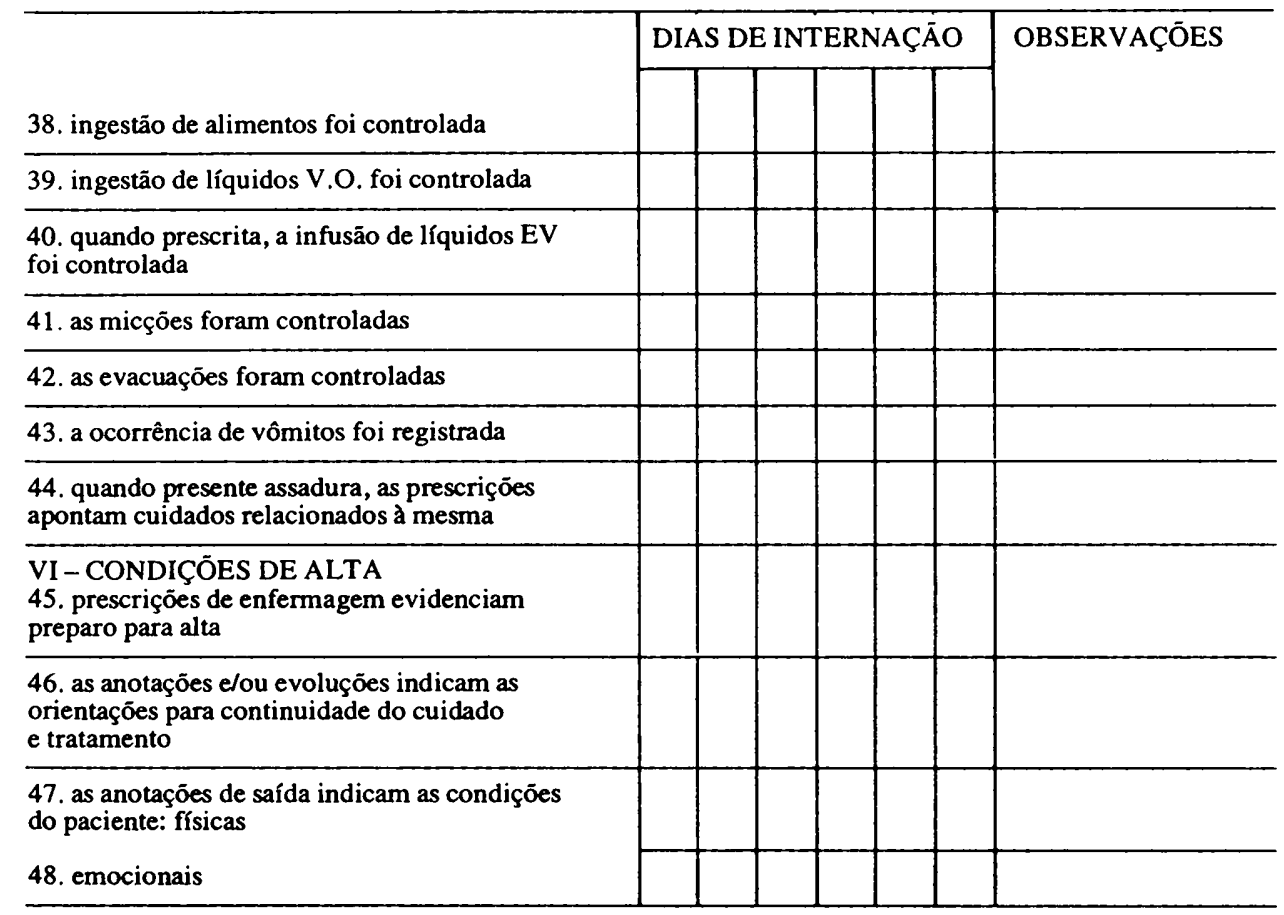




\section{LISTA DE PROBLEMAS}

Problemas levantados

Problemas abordados: entrevista

exame físico

evolução de entrada

\section{Posteriores}




\section{INSTRUMENTO - CRITÉRIOS ADOTADOS PARA O PREENCHIMENTO}

\begin{tabular}{|c|c|}
\hline Áreas - componentes & Critérios adotados \\
\hline $\begin{array}{l}\text { I - Levantamento de dados na admissão } \\
1 \text { - dados de identificação completos }\end{array}$ & $\begin{array}{l}\text { Os dados de identificação são os que } \\
\text { compöem o cabeçalho da folha do } \\
\text { histórico até o item: nome } \\
\text { do entrevistado. } \\
\text { Total de itens: } 14 \\
\qquad 14=\text { sim } \\
13 \text { a } 7=\text { incompleto } \\
\quad 6 \text { a } 0=\text { não } \\
\text { Nota: especificar na coluna de } \\
\text { observaçōes o no dos itens } \\
\text { não preenchidos. }\end{array}$ \\
\hline $\begin{array}{l}2 \text { - entrevista preenchida de forma } \\
\text { correta e por completo }\end{array}$ & $\begin{array}{l}\text { correta = resposta pertinente à pergunta } \\
\text { completo = resposta preenchida ou } \\
\text { com um traço } \\
\text { Total de itens: } 56 \\
\quad 56=\text { sim } \\
55 \text { a } 28=\text { incompleto } \\
27 \text { a } 0=\text { não }\end{array}$ \\
\hline $\begin{array}{l}3 \text { - exame físico preenchido de forma } \\
\text { correta e por completo }\end{array}$ & $\begin{array}{l}\text { correta = resposta pertinente à pergunta } \\
\text { completo = resposta preenchida ou } \\
\text { com um traço } \\
\text { Total de itens: } 43 \\
\quad 43=\text { sim } \\
43 \text { a } 22=\text { incompleto } \\
21 \text { a } 0=\text { não }\end{array}$ \\
\hline
\end{tabular}

NOTA: 1. as respostas em branco sem traço serão consideradas como não respondidas.

2. as questōes que apresentam sub-itens só serão consideradas respondidas quando, nos casos de resposta afirmativa, os sub-itens tiverem sido respondidos.

3. anotar na coluna de observações o número das questōes que não foram respondidas. 


\begin{tabular}{|c|c|}
\hline Áreas - componentes & Critérios adotados \\
\hline $\begin{array}{l}4 \text { - levantamento permite identificar } \\
\text { as condiçōes físicas }\end{array}$ & $\begin{array}{l}\text { as condições físicas são identificadas: } \\
\text { todo exame físico ( } 49 \text { itens) + dados } \\
\text { evolução entrada + impressão } \\
\text { do examinador: } \\
\text { sim }=32 \text { itens E. Físico + sinais } \\
\text { e sintomas. } \\
\text { incompleto = } 21 \text { a } 32 \text { itens E.F. + sinais } \\
\text { e sintomas. } \\
\text { não = menos de } 21 \text { itens E.F. sem sinais } \\
\text { e sintomas }\end{array}$ \\
\hline $\begin{array}{l}5 \text { - Levantamento de dados permite } \\
\text { identificar as condições emocionais } \\
\text { no momento da internação }\end{array}$ & $\begin{array}{l}\text { sim = houve menção das } \\
\text { condiçōes emocionais da criança. } \\
\text { não = não houve menção das } \\
\text { condiçōes emocionais da criança. } \\
\text { Nota: esta informação poderá estar: } \\
\text { evolução entrada, outras } \\
\text { informaçōes ou impressões } \\
\text { do examinador. }\end{array}$ \\
\hline $\begin{array}{l}6 \text { - Levantamento de dados permite } \\
\text { conhecimento dos hábitos relacionados } \\
\text { ao atendimento das necessidades } \\
\text { psicobiológicas }\end{array}$ & $\begin{array}{l}\text { indicam atendimento às necessidades } \\
\text { psicobiológicas as questōes } n=1,2,3 \\
\text { e } 15 \text { a } 35 \\
\text { Total de itens }=24 \\
\text { sim }=24 \\
\text { incompleto }=12 \text { a } 23 \\
\text { não = menos de } 12\end{array}$ \\
\hline 7 -psicossociais & $\begin{array}{l}\text { indicam necessidades psicossociais } \\
\text { questōes no } 4 \text { a } 14 \text { e } 36 \text { a } 55 \\
\text { Total de itens }=31 \\
\text { sim }=31 \\
\text { incompleto }=16 \text { a } 30 \\
\text { não }=0 \text { a } 15\end{array}$ \\
\hline
\end{tabular}




\begin{tabular}{|c|c|}
\hline Áreas - componentes & Critérios adotados \\
\hline 8 - psicoespirituais & $\begin{array}{l}\text { não existe questão referente ao aspecto } \\
\text { psicoespiritual, porém a informação } \\
\text { poderá estar registrada em qualquer } \\
\text { parte do histórico ou ao final do } \\
\text { exame físico. } \\
\text { sim = quando existe a informação } \\
\text { não = quando não existe a informação. }\end{array}$ \\
\hline 9 - Levantamento datado e assinado. & $\begin{array}{l}\text { data - cabeçalho do histórico - } \\
\text { item = histórico em ... assinatura = ao } \\
\text { final do histórico ou do exame } \\
\text { físico ou em ambos. } \\
\text { sim = constam data e assinatura } \\
\text { incompleto = falta data ou assinatura } \\
\text { não = faltam data e assinatura } \\
\text { Anotar na coluna de observação o } \\
\text { dado em falta. }\end{array}$ \\
\hline $\begin{array}{l}\text { II - Prescrição e evoluções } \\
\text { de enfermagem } \\
10 \text { - A primeira prescrição é feita pela } \\
\text { mesma enfermeira que realizou } \\
\text { o levantamento. }\end{array}$ & $\begin{array}{l}\text { Conferir assinatura da prescrição e } \\
\text { levantamento. } \\
\text { sim = assinaturas indicam mesma pessoa } \\
\text { não = assinaturas indicam pessoas } \\
\text { diferentes } \\
\text { Em caso negativo anotar a justificativa } \\
\text { na coluna de observaçōes. }\end{array}$ \\
\hline $\begin{array}{l}11 \text { - Primeira prescrição reflete os } \\
\text { problemas levantados }\end{array}$ & $\begin{array}{l}\text { Verificar a listagem dos problemas } \\
\text { (histórico + Exame Físico) + Evolução } \\
\text { de entrada e verificar se a prescrição } \\
\text { reflete os mesmos. } \\
\text { Do no total de problemas } \\
\text { sim }=\text { de } 50 \% \text { a } 100 \% \\
\text { não }=\text { menos de } 49 \%\end{array}$ \\
\hline
\end{tabular}


12 - "Evolução de entrada" possibilita verificar as condiçōes gerais do paciente
Evolução de entrada deve fazer um resumo das condiçōes físicas e emocionais no momento da internaçāo. a - sinais e sintomas físicos + alimentação + eliminações. b - condiçōes emocionais sim $=$ tem item a e b incompleto $=$ não tem item $\mathbf{a}$ ou $b$ não $=$ não tem item $a$ nem $b$ Anotar na coluna de observação o dado que faltou, se físico ou emocional.

13 - Há uma prescrição diária

Verificar se há uma prescrição diária para cada dia de internação

Prescrição tem validade de 24 horas sim = há uma para cada dia de internação não = faltam uma ou mais prescriçōes.

14 - Prescrição estruturada na seqüência determinada
Verificar em cada prescrição a seguinte seqüência:

1. controles -2 . alimentação -

3. higiene -4 . sinais e sintomas -

5. tratamentos (curativos, preparação de exames) -6 . orientaçāo 7. assistência espiritual 8. encaminhamentos. sim = observa seqüência na íntegra não = não observa seqüência na íntegra 


\begin{tabular}{|c|c|}
\hline Áreas - componentes & Critérios adotados \\
\hline $\begin{array}{l}15 \text { - Prescrição indica o grau de } \\
\text { dependência do paciente. }\end{array}$ & $\begin{array}{l}\text { Grau de dependência é indicado } \\
\text { pelo verbo } \\
\text { Total - fazer, ministrar, aplicar, medir, } \\
\text { limpar, mobilizar, executar, colocar, etc. } \\
\text { Parcial - ajudar, auxiliar, apoiar, } \\
\text { oferecer, permitir, vigiar, fornecer, } \\
\text { acompanhar. } \\
\text { sim = quando indica grau } \\
\text { não = quando não indica grau } \\
\text { Na coluna de observação colocar se } \\
\text { dependência Total ou parcial. }\end{array}$ \\
\hline $\begin{array}{l}16 \text { - Prescrição indica açōes } \\
\text { relacionadas ao atendimento das } \\
\text { necessidades psicobiológicas } \\
17 \text { - psicossociais } \\
18 \text { - psicoespirituais }\end{array}$ & $\begin{array}{l}\text { na coluna observações listar as } \\
\text { necessidades abordadas } \\
\text { idem às psicobiológicas } \\
\text { idem às psicobiológicas }\end{array}$ \\
\hline $\begin{array}{l}19 \text { - Prescrição de enfermagem aborda } \\
\text { problemas anteriores e novos }\end{array}$ & $\begin{array}{l}\text { Verificar a listagem de problemas }+ \\
\text { evolução que antecede a prescrição } \\
\text { do dia. } \\
\text { Do total de problemas: } \\
\text { sim }=60 \text { a } 100 \% \\
\text { incompleta }=59 \text { a } 40 \% \\
\text { não }=\text { menos de } 40 \%\end{array}$ \\
\hline $\begin{array}{l}20 \text { - Prescrição aponta cuidados } \\
\text { referentes à terapêutica médica } \\
\text { prescrita }\end{array}$ & $\begin{array}{l}\text { Ler a prescrição médica correspondente } \\
\text { e verificar os itens que demandam } \\
\text { açōes de enfermagem a serem } \\
\text { explicitadas na prescrição de } \\
\text { enfermagem. } \\
\text { sim = todos os itens abordados }=100 \% \\
\text { incompleta }=50 \% \text { a } 99 \% \text { abordados ou } \\
\text { então abordados de maneira incompleta } \\
\text { não = menos de } 49 \% \text { abordados } \\
\text { não se aplica - quando na prescrição } \\
\text { médica não existem itens que demandem } \\
\text { açōes de enfermagem a serem } \\
\text { explicitadas na prescrição de } \\
\text { enfermagem. }\end{array}$ \\
\hline
\end{tabular}




\begin{tabular}{|c|c|}
\hline Áreas - componentes & Critérios adotados \\
\hline $\begin{array}{l}21 \text { - Prescrição tem data, horário e } \\
\text { assinatura }\end{array}$ & $\begin{array}{l}\text { Toda prescrição deve ter os três itens } \\
\text { sim = tem os três itens } \\
\text { incompleta = falta um item } \\
\text { não = faltam dois ou três itens } \\
\text { Anotar na observações o que ficou } \\
\text { faltando. }\end{array}$ \\
\hline $\begin{array}{l}22 \text { - Os cuidados prescritos foram } \\
\text { checados }\end{array}$ & $\begin{array}{l}\text { Verificar checagem } \\
\text { Do total de itens } \\
\text { sim }=100 \% \\
\text { incompleto }=50 \text { a } 99 \% \\
\text { não = menos de } 49 \%\end{array}$ \\
\hline $\begin{array}{l}23 \text { - Há uma evolução antecedendo } \\
\text { cada prescrição }\end{array}$ & $\begin{array}{l}\text { Verificar se há uma evolução para } \\
\text { cada prescrição. } \\
\text { sim = quando há } \\
\text { não= quando não há }\end{array}$ \\
\hline $\begin{array}{l}24 \text { - Evolução possibilita visão geral } \\
\text { das condições do paciente }\end{array}$ & $\begin{array}{l}\text { A evolução deve conter: } \\
\text { - estado emocional } \\
\text { - temperatura } \\
\text { - eliminações } \\
\text { - alimentação, hidratação } \\
\text { - intercorrências } \\
\text { - sinais e sintomas } \\
\text { sim }=100 \% \\
\text { incompleto = de } 50 \text { a } 99 \% \\
\text { não = menos de } 49 \% \\
\text { Na observação especificar o que } \\
\text { ficou faltando }\end{array}$ \\
\hline $\begin{array}{l}25 \text { - Evolução fornece informaçōes } \\
\text { dos resultados dos cuidados prestados }\end{array}$ & $\begin{array}{l}\text { Verificar prescrição anterior e na } \\
\text { evolução seguinte as informaçōes } \\
\text { sobre o resultado dos cuidados. } \\
\text { sim }=100 \% \\
\text { incompleto }=50 \text { a } 99 \% \\
\text { não }=\text { menos de } 49 \%\end{array}$ \\
\hline
\end{tabular}




\begin{tabular}{|c|c|}
\hline Áreas - componentes & Critérios adotados \\
\hline $\begin{array}{l}26 \text { - Evolução tem data, horário e } \\
\text { assinatura }\end{array}$ & $\begin{array}{l}\text { Verificar presença dos três dados. } \\
\text { Como prescrição e evolução são } \\
\text { contínuas, os dados são válidos } \\
\text { para ambas. } \\
\text { sim }=3 \text { itens } \\
\text { incompleto }=2 \text { itens } \\
\text { não = faltam } 2 \text { ou } 3 \text { itens } \\
\text { Anotar na observaçõa o dado que } \\
\text { ficou em falta }\end{array}$ \\
\hline $\begin{array}{l}\text { III - Anotaçōes de enfermagem } \\
27 \text { - há pelo menos } 1 \text { anotaçāo em } \\
\text { cada plantão }\end{array}$ & $\begin{array}{l}\text { Padrão estabelecido }-1 \text { anotação } \\
\text { por plantão. } \\
\text { manhã }=7: 30 \text { às } 13: 30 \mathrm{hs} \\
\text { tarde }=13: 30 \text { às } 19: 30 \mathrm{hs} \\
\text { noite }=19: 30 \text { às } 7: 30 \mathrm{hs} \\
\text { sim }=1 \text { por plantão } \\
\text { não = quando não há } 1 \text { por plantão }\end{array}$ \\
\hline $\begin{array}{l}28 \text { - anotaçōes respondem os itens } \\
\text { da prescrição }\end{array}$ & $\begin{array}{l}\text { comparar anotações e prescrições do } \\
\text { dia e verificar se respondem as } \\
\text { açōes indicadas: } \\
\text { sim }=100 \% \\
\text { incompleta }=99 \text { a } 50 \% \\
\text { não }=49 \text { a } 0 \%\end{array}$ \\
\hline $\begin{array}{l}29 \text { - anotaçōes evidenciam } \\
\text { observaçōes de sinais e sintomas }\end{array}$ & $\begin{array}{l}\text { verificar se as anotaçōes denotam } \\
\text { observação de sinais e sintomas. } \\
\text { sim }=100 \% \\
\text { incompleta }=99 \text { a } 50 \% \\
\text { não }=49 \text { a } 0 \%\end{array}$ \\
\hline $\begin{array}{l}30 \text { - horários e rubrica em } \\
\text { cada anotação }\end{array}$ & $\begin{array}{l}\text { como horário e rubrica são condiçōes } \\
\text { que validam a anotação, verificar se } \\
\text { cada anotação tem horário e rubrica. } \\
\text { sim }=100 \% \\
\text { incompleto }=99 \text { a } 50 \% \\
\text { não }=49 \text { a } 0 \%\end{array}$ \\
\hline
\end{tabular}




\begin{tabular}{|c|c|}
\hline Áreas - componentes & Critérios adotados \\
\hline $\begin{array}{l}31 \text { - anotação indica a categoria } \\
\text { de quem a realizou (enf. tec. } \\
\text { aux. atend.) }\end{array}$ & $\begin{array}{l}\text { verificar se após a rubrica tem a sigla } \\
\text { indicando a categoria do elemento } \\
\text { que realizou a anotação } \\
\text { sim }=100 \% \\
\text { incompleto }=95 \text { a } 50 \% \\
\text { não }=49 \text { a } 0 \%\end{array}$ \\
\hline $\begin{array}{l}\text { IV - Execução de ordens médicas } \\
32 \text { - medicação dada checada } \\
\text { e rubricada }\end{array}$ & $\begin{array}{l}\text { verificar se todos os horários foram } \\
\text { checados e rubricados } \\
\text { Total dos itens } \\
100 \%=\text { sim } \\
50 \text { a } 90 \%=\text { incompleto } \\
0 \text { a } 49 \%=\text { não }\end{array}$ \\
\hline 33 - tratamentos checados e rubricados & $\begin{array}{l}\text { verificar se todos os horários } \\
\text { estabelecidos foram checados } \\
\text { e rubricados. } \\
\text { Total de itens } \\
100 \%=\text { sim } \\
50 \text { a } 90 \%=\text { incompleto } \\
0 \text { a } 49 \%=\text { não }\end{array}$ \\
\hline $\begin{array}{l}34 \text { - anotada com hora e rubricada } \\
\text { ocorrência com medicação } \\
\text { e tratamento }\end{array}$ & $\begin{array}{l}\text { verificar se as medicações e } \\
\text { tratamentos não checados ou circulados } \\
\text { foram justificados. } \\
\text { sim = quando houve anotação } \\
\text { da ocorrência } \\
\text { não = quando não houve anotação } \\
\text { da ocorrência }\end{array}$ \\
\hline $\begin{array}{l}35 \text { - ordens médicas não indicam } \\
\text { ações de enfermagem }\end{array}$ & $\begin{array}{l}\text { as ordens médicas não devem indicar } \\
\text { açōes próprias de enfermagem. } \\
\text { sim = quando as ordens médicas não } \\
\text { indicam açōes de enfermagem } \\
\text { não = quando as ordens médicas } \\
\text { indicam ações de enfermagem }\end{array}$ \\
\hline
\end{tabular}




\begin{tabular}{|c|c|}
\hline Áreas - componentes & Critérios adotados \\
\hline $\begin{array}{l}\text { V - Procedimentos de enfermagem } \\
36 \text { - controle de temperatura feito } \\
\text { no mínimo } 2 \text { vezes ao dia }\end{array}$ & $\begin{array}{l}\text { verificar no gráfico se cada dia de } \\
\text { internação corresponde } 2 \text { controles } \\
\text { de temperatura. } \\
\text { sim }=2 \text { controles registrados } \\
\text { não }=1 \text { ou nenhum controle registrado }\end{array}$ \\
\hline $\begin{array}{l}37 \text { - peso controlado } 1 \text { vez ao } \\
\text { dia no mínimo }\end{array}$ & $\begin{array}{l}\text { verificar no gráfico se há } 1 \text { controle de } \\
\text { peso registrado por dia. } \\
\text { sim }=1 \text { controle } \\
\text { não }=\text { sem controle anotado }\end{array}$ \\
\hline $\begin{array}{l}38 \text { - ingestão de alimentos foi } \\
\text { controlada }\end{array}$ & $\begin{array}{l}\text { verificar no impresso de controles } \\
\text { especiais, se diariamente está anotada } \\
\text { a ingestão do alimento nos } \\
\text { horários especificados } \\
\text { sim = quando há anotação em todos } \\
\text { os horários } \\
\text { não = quando não há anotação em } \\
\text { todos os horários }\end{array}$ \\
\hline $\begin{array}{l}39 \text { - ingestão de líquidos V.O. } \\
\text { foi controlada }\end{array}$ & idem 38 \\
\hline $\begin{array}{l}40 \text { - quando prescrita a infusão de } \\
\text { líquidos EV. foi controlada }\end{array}$ & $\begin{array}{l}\text { verificar na coluna de horário da } \\
\text { prescrição médica, hora do início e } \\
\text { término da infusão, comparando com } \\
\text { o que foi prescrito } \\
\text { sim = anotado horário do início e } \\
\text { término da infusão e observa o } \\
\text { prazo prescrito } \\
\text { não = quando falta horário de início ou } \\
\text { término e/ou o prazo prescrito não } \\
\text { foi observado } \\
\text { não aplicável = quando não há } \\
\text { prescrição de infusão EV. }\end{array}$ \\
\hline
\end{tabular}




\begin{tabular}{|c|c|}
\hline Áreas - componentes & Critérios adotados \\
\hline 41 - as micçōes foram controladas & $\begin{array}{l}\text { verificar na folha de controles especiais } \\
\text { se as miç̧ōes foram anotadas. } \\
\text { sim = quando as micções foram } \\
\text { anotadas } \\
\text { não = quando as micções não foram } \\
\text { anotadas }\end{array}$ \\
\hline 42 - as evacuações foram anotadas & $\begin{array}{l}\text { verificar na folha de controles especiais } \\
\text { se as evacuaçōes foram anotadas. } \\
\text { sim = quando as evacuaçōes foram } \\
\text { anotadas ou então mencionada a } \\
\text { não evacuação } \\
\text { não = quando não há nenhum registro } \\
\text { referente a evacuação }\end{array}$ \\
\hline $\begin{array}{l}43 \text { - a ocorrência de vômitos foi } \\
\text { registrada }\end{array}$ & $\begin{array}{l}\text { verificar na folha de controles especiais } \\
\text { se há registro de vômito - ler as } \\
\text { anotaçōes e evoluções do dia para } \\
\text { comparação. } \\
\text { sim = quando há registro na folha } \\
\text { de controle } \\
\text { não = quando não há registro na folha } \\
\text { de controle porém aparecem vômitos } \\
\text { mencionados nas evoluções } \\
\text { não aplicável = não há nenhum registro } \\
\text { de vômitos }\end{array}$ \\
\hline $\begin{array}{l}44 \text { - quando presente a assadura, as } \\
\text { prescriçōes apontam cuidados } \\
\text { relacionados à mesma }\end{array}$ & $\begin{array}{l}\text { verificar exame físico-evoluçōes e } \\
\text { anotações de enfermagem para } \\
\text { constatar presença de assadura. } \\
\text { sim = quando assadura presente e as } \\
\text { prescriçōes de enfermagem } \\
\text { apontam cuidados } \\
\text { não= quando assadura presente e as } \\
\text { prescriçōes não apontam cuidados } \\
\text { não aplicável = quando não há } \\
\text { registro de assadura }\end{array}$ \\
\hline
\end{tabular}




\begin{tabular}{|l|l|}
\hline \multicolumn{1}{|c|}{ Áreas - componentes } & \multicolumn{1}{|c|}{ Critérios adotados } \\
\hline $\begin{array}{l}\text { VI - Condições de alta } \\
45 \text { - prescriçōes de enfermagem } \\
\text { evidenciam preparo para alta }\end{array}$ & $\begin{array}{l}\text { verificar se nas prescriçōes de } \\
\text { enfermagem há indício de preparo } \\
\text { para alta. } \\
\text { sim }=\text { quando há } \\
\text { não }=\text { quando não há }\end{array}$ \\
\hline $\begin{array}{l}\text { 46 - as anotações e ou evoluções } \\
\text { indicam orientações para continuidade } \\
\text { do tratamento }\end{array}$ & idem ao 45, só que nas evoluçōes \\
\hline $\begin{array}{l}47 \text { - as anotaçōes de saída indicam } \\
\text { condições físicas do paciente }\end{array}$ & $\begin{array}{l}\text { sim = quando indicam } \\
\text { não }=\text { quando não indicam }\end{array}$ \\
\hline $\begin{array}{l}48 \text { - as anotaçōes de saída indicam } \\
\text { condiçōes emocionais do paciente }\end{array}$ & $\begin{array}{l}\text { sim = quando indicam } \\
\text { não = quando não indicam }\end{array}$ \\
\hline
\end{tabular}

Nota: Para responder as questões de 1 a 13, assinalar com um X coluna correspondente.

Para as questōes de 14 a 44, utilizar no preenchimento da coluna correspondente os numerais conforme segue:

$$
\begin{aligned}
& \text { sim }=3 \\
& \text { incompleto }=2 \\
& \text { não }=1 \\
& \text { nāo se aplica }=0
\end{aligned}
$$




\section{CONCLUSŌES E CONSIDERAÇŌES FINAIS}

O instrumento proposto, está sendo utilizado desde 1983 no Hospital Universitário da Universidade de São Paulo, tendo sido realizadas modificações na área V. do mesmo para atender às especificidades de cada unidade de internação.

A finalidade precípua da utilização da auditoria é a melhoria da qualidade da assistência de enfermagem prestada na instituição. A aplicação contínua da mesma tem permitido ao Departamento de Enfermagem:

- caracterizar o nível de atuação da enfermagem nas diversas unidades de internaçāo;

- identificar os aspectos deficientes relacionados à assistência de enfermagem proposta;

- motivar a equipe de enfermagem melhorar o nível de assistência de enfermagem prestada;

- obter dados para elaboração dos programas de atualização e reciclagem do pessoal de enfermagem;

- garantir a qualidade dos registros da assistência de enfermagem;

- subsidiar a elaboração de novos programas assistenciais e reelaborar os existentes.

A auditoria em enfermagem, representa a função "controle" do ciclo do processo administrativo, sob a qual o departamento de enfermagem conduz suas funçōes básicas, direcionando a assistência prestada ao atendimento das reais necessidades apresentadas por seus clientes e pacientes, contribuindo assim, para a melhoria do nível de saúde da comunidade.

SILVA, S.H. Auditory in nursing: proposal of an instrument. Rev. Esc. Enf. USP, São Paulo, 23(3):305-323, dez. 1989.

The author purposes an instrument of retrospective auditory for the assiessment of the nursing care given to each patient by means of his/her documentation. The instrument was elaborated based on the assistencial patterns and the norms of the nursing care program established for the unit.

UNITERMS: Nursing audit. Nursing care.

\section{REFERÊNCIAS BIBLIOGRÁFICAS}

ABDELlAH, F.C. Critérios de avaliação em enfermagem. Rev. Bras. Enf., Rio de Janeiro, 26(1/2): 17-32, jan./fev. 1973.

AQUINO, C.B. de. Administraçăo de recursos humanos: uma introdução. São Paulo, Atlas, 1980. $270 \mathrm{p}$.

BERG, H.U. Nursing audit and entcome criteria. Nurs. Clin. North Am., Philadelphia, 9(2): 331-5, June 1974.

ChIA Venato, I. Administração de recursos humanos. 2. ed. São Paulo, Atlas, 1981. 375 p.

KRON, T. Manual de enfermagem. 4. ed. Rio de Janeiro, Interamericana, 1978. 251 p.

KURCGANT, P. Auditoria em enfermagem. Rev. Bras. Enf., Brasília, 29(3): 106-24, jul./set. 1976.

SÁ, A.L. de. Curso de auditoria. 5. ed. São Paulo, Atlas, 1969. 250 p.

Recebido em 09/08/88

Rev. Esc. Enf. USP, São Paulo, 23(3):305-323, dez. 1989 